\title{
DISTANCE EDUCATION DURING THE COVID-19 PANDEMIC
}

\author{
Ekaterina Kupchina \\ Associate professor, RUDN University, RUSSIA belousova-ev@rudn.ru
}

\begin{abstract}
In the XXI century, the world has faced with a pandemic caused by the COVID-19 virus. Measures taken by the governments of most states to prevent the spread of the new coronavirus infection have led to the transition of the entire education system to a distance format.

Initially, the distance learning format was created and perceived as an alternative to traditional approaches to the training system. Modern technologies and global digitalization have become the starting point towards the implementation of this educational method. However, self-isolation and the need to maintain social distance have brought distance learning to a fundamentally new level. Many higher educational institutions, including those in Russia, were ready for this transition. Nevertheless, in the process of implementing distance learning, significant shortcomings were identified. Social surveys among students conducted during the pandemic's onset showed a relatively high percentage of satisfaction with the transition to the remote format.
\end{abstract}

However, after a few months, a second survey showed that the initial indicators had dropped significantly. The most frequently encountered problems were social distance and lack of communication with classmates, problems with the use of technology and interruptions in the Internet, lack of face-to-face communication with the teacher and group discussions, difficulties in organizing self-control and independent study of the material, increased workload and time consuming while completing the assignments. Even many more problems have arisen in universities where international groups exist. Difficulties in mental perception and language barriers cause the most significant difficulties.

In this article, the author analyzes the existing distance learning system implemented during the COVID-19 pandemic.

The study's result is to identify the advantages and disadvantages of implementing this training format to develop recommendations for its improvement in the practice of higher educational institutions in the Russian Federation.

The article aims at:

- Identifying and analyzing the main methods and means of implementing the distance learning format in higher educational institutions;

- Identifying the main trends associated with the reform of the higher education system as a whole;

- Developing recommendations for improving the distance learning system.

The research's methodological basis is formed by general scientific methods of cognition, including systemic, formal-logical, and structural-functional analysis. The research's scientific novelty lies in a comprehensive study of the problems arising in the higher education system and the use of a distancelearning format, identifying positive and negative aspects in the implementation of this approach to learning.

The results of this research can be used in the development of training courses, educational and methodological sets, and improving the higher education system. This article's conclusions and materials can be used in research, teaching, lectures, and seminars in the relevant disciplines.

Keywords: higher education, distance learning, digitalization, e-courses. 


\section{INTRODUCTION}

Distance education is a relatively new phenomenon. The first attempts to attract a wide audience to university disciplines at a distance were made at the end of the 19th century at the University of London. Over time, under the influence of various factors, distance learning has become even more widespread. These factors include the development of state programs aimed at maintaining and developing higher education, improving and developing digital technologies, the desire of society to self-study and improve their qualifications.

The emergence of distance learning is an adequate response to the changing social needs of society. The global digitalization of all spheres of human life, as well as the desire for lifelong learning, have served as a new round in the development of methods for the implementation of this form of education.

The situation faced by the entire education system worldwide related to the spread of COVID-19 is an unprecedented case. Following the announcement by the World Health Organization (WHO) in February, 2020 of the novel coronavirus pandemic and the imposition of social distancing and self-isolation measures by governments, more than 1.5 billion students worldwide have been cut off from university attendance. Undoubtedly, the emergency measures taken could not but affect the quality of education, as well as the psycho and emotional state of students. The rapid transition from traditional teaching methods to a distance format made it possible to identify the main positive and negative aspects in the implemented methods of teaching, as well as develop some recommendations for improving the higher education system.

\section{METHODOLOGY}

The main research methods are general scientific methods of cognition, including systemic, formal-logical, structural-functional analysis. The study of the problems arising in the higher education system as a whole, and in the application of the distance learning format, was carried out through specific research, logical, statistical and content analysis. During the work on the topic, the author relied on research conducted by the un department of economic and social affairs, the international labor organization, the world trade organization, and the opinions of Russian and foreign theoretical scientists in the considered and related fields of knowledge.

\section{RESULTS}

\subsection{Impact of the COVID-19 Pandemic on the Distance Learning system}

\subsubsection{The Main Positive Factors of the Transition to Distance Learning Format}

Despite all the difficulties associated with the transition to distance learning during the COVID-19 pandemic, many Russian and foreign higher educational institutions were ready to it. Modern digital technologies made it possible to make this transition as quickly as possible, although, even three to four decades ago, such a situation would mean only one thing - a complete cessation of educational processes (Irina Gronik, 2020).

Initially, the distance learning system was developed as an alternative to existing traditional formats. The main goals of its creation include:

- Reducing the cost of training, which makes it possible to attract the widest possible audience to the appropriate level of education;

- A wide range of professions implemented by distance learning programs;

- A flexible schedule of the educational process, allowing the working population to get higher education;

- The ability to vary the duration of training.

However, the COVID-19 pandemic has left its mark on distance learning. The work on the preparation of online courses and creation of digital educational environment has been carried out by many universities over the past years, which made it possible, without a significant loss in the quality of education, to transfer more than a million courses to a distance format. (Ekaterina Kupchina, 2020)

Surveys conducted among students and teachers at the very beginning of the self-isolation regime showed a high percentage of satisfaction with this teaching format. The respondents referred to the positive aspects as:

- The growth of students' subjective attitude in relation to their educational trajectory - according to certain programs, there is an increase in the attendance of classes (37\%); 
- Increased sleep for recreation, due to the lack of the need to spend time on the way to universities (64\%);

- Increase in personal time, the ability to engage in hobbies (49\%);

- Reduction of study fatigue (55\%). (IAU., 2020)

As for the teaching staff of universities, four groups can be distinguished, which reacted differently to the processes taking place in the education system. The first group includes teachers of disciplines that require a significant amount of practical and laboratory work. With regard to this category, there have been no major changes in the organization of teaching methods. They continued their engagement in methodological and organizational work, and helped other teachers.

The second group includes educators who were actively using digital technologies, including online courses, even before the pandemic. This category was able to quickly adapt and make an almost painless transition to a distance learning system. A survey among the teachers of this group showed that, in general, their attitude to this format of training is positive and, in their opinion, the expansion of the use of the distance format does not have a significant impact on the quality of training for a particular course in the online format and can be comparable with the quality of training in a traditional format.

The third group includes the largest percentage of teachers who are familiar with digital technologies, including outside the implementation of their main professional activities. Before the pandemic, their level of digital skills was limited to searching for information on the Internet and communicating via e-mail. They were also able to quickly learn new teaching tools, but it took a lot of effort. Despite the difficulties in mastering new approaches to the training system, this group also has a positive opinion regarding the distance learning format. However, due to the increased workload associated with the development of new instruments, the teachers of this group see the possibility of using this method only in some cases, as an additional means of monitoring the obtaining of the material.

The fourth group includes teachers who have not been able to master digital technologies in the organization of training. For them, the experience of switching to a distance format was very painful. In fact, students studying in groups with these teachers switched to an extramural learning format and received assignments and recommendations for their assignment by e-mail.

Summarizing the above examples, we can conclude that, despite the difficulties faced by many teachers during the pandemic, the massive transition to a distance learning format has significantly increased the level of digital literacy among teachers through the active use of online communication tools, and training university-based webinars.

In addition, the experience of universities working in a distance format made it possible to identify among some universities a lag behind modern requirements in the field of management and organization of the educational process, which is a catalyst for revising the entire system of effective management of the educational process (Belousova A., 2017)

A conscious approach to new opportunities for higher education makes it possible to take a new step towards the development of the competitiveness of higher education in Russia.

\subsubsection{The Main Negative Factors of the Transition to Distance Learning Format}

The situation with the spread of coronavirus infection has affected all areas of human relationships. In the first months of the pandemic, national governments had to take unprecedented measures to prevent the spread and reduce the infection of COVID-19. The sphere of education is the most sensitive to the ongoing changes and, although it turned out to be one of the few most prepared, the consequences of a full-scale transition to a distance format can only be assessed after a while.

Among the main problems that arose in the field of education during the pandemic, the first and crucial one is the reduction in funding. A decline in academic mobility and an increase in the number of unemployed people have significantly reduced university revenues. Left without work, many students were simply unable to pay for their studies. In this regard, many universities have taken measures aimed at social support of students. For students who remained in dormitories for the period of self-isolation, the accommodation fee was canceled or significantly reduced. In the absence of technical means that meet all the requirements for organizing distance learning, computers were provided to these students. With regard to tuition fees, it was recommended to develop a flexible payment system (deferral, installment plan). All these measures could not but affect the deterioration of the financial condition of the universities.

Also, according to a survey conducted by the International Association of Universities, in the near future, the 
decline in academic mobility may be up to $89 \%$, which will negatively affect the financial condition of universities. It is expected that, first of all, the decline in incoming academic mobility will affect the countries that traditionally received the largest number of foreign applicants, such as the USA, Italy, Great Britain, and alike, due to the high number of infection among their population.

Undoubtedly, the crucial way out of this situation is the widespread use of digital technologies and distance learning. (Dudin, M.N., 2019) However, according to the research conducted, when transferring training programs to online format, universities do not intend to reduce the cost of education. This is explained by the fact that the costs of educational organizations for material and technical support and marketing are significantly higher than with traditional training. An important role in this matter is also played by the recognition of universities at the international level. (Dudin, M.N., 2017)

The organization of communication can also be attributed to the problems associated with attracting international students in a distance learning format. Even with personal communication with classmates and teachers, international students experience stress due to differences in mental perception, as well as due to language difficulties. Distance learning only exacerbates this situation. The measures taken by universities aimed at preserving the number of international students still allow maintaining the share of these students at practically the same level as before the pandemic. However, given the experience already gained, universities will need to rethink their internationalization strategies in collaboration with national ministries of education. (Dudin, M.N., 2018)

National surveys conducted among students also revealed several negative factors in the widespread use of distance learning, which have an impact on educational processes and social relationships. This primarily concerns students of technical and medical professions. The main component of the educational process in this category is practical training, which is rather difficult to implement with distance learning. With regard to medical professions, the way out of this situation was the possibility of sending senior students (at will) to medical organizations to assist medical workers in the fight against the spread of coronavirus infection. There were much more difficulties with technical specialties. Many universities of a technical orientation have decided to postpone their practice for the year to come or have shifted the beginning of the educational process to a later date.

In social relationships, the negative impact of the distance learning is also noted. Cut off from face-to-face communication with fellow students and teachers, many students experienced stress. Most of the respondents note that they feel discomfort when the teacher asks to turn on the camera, and they are also embarrassed to ask the teacher questions online.

Many universities have faced the lack of a developed digital infrastructure for organizing distance learning. (Inshakova, A.O., 2016) In this regard, universities with their own digital educational platforms have provided general access to their online resources. Such courses were published on online platforms, posted on specially created electronic resources or sections of official websites. Platforms such as Coursera and Open Education have also opened access to their online courses. However, these measures were able to provide only an initial transition to distance learning mode and made it possible to fill the existing gaps in the digital environment of universities. Nevertheless, despite the measures taken, many teachers and students continued to conduct classes in the so-called "asynchronous" mode, sending assignments by e-mail, which in fact led to a correspondence mode. Also, the monitoring showed that about 90 percent of students independently study educational materials sent by teachers and, as a result, note a significant increase in the teaching load. This primarily applies to junior students. It was found that most universities do not provide any support in terms of organizing students' independent work. This is due to the fact that in some universities there are not enough electronic library resources or they lack them. Only a small number of students used digital learning management systems when preparing homework and organizing independent work.

Among the teaching staff of universities, there is also a high degree of dissatisfaction with the large-scale use of distance learning. Educational materials prepared for offline classes are not always possible to adapt to the online learning format, which significantly reduces the percentage of students' involvement in the educational process. As a consequence of the lack of students' motivation, there is a risk that they may simply drop out.

The need to transfer most of the courses online creates a significant burden for teachers. The time for downloading materials and checking student assignments increases. 


\section{CONCLUSION}

As seen from the study, at this stage of the widespread use of distance learning during pandemic, negative characteristics largely prevail.

After more than six months of mass application of this technology, it can be concluded that, in general, the higher education system coped with this situation. The measures taken to quickly switch the entire educational system to online mode, horizontal communications and the restructuring of the activities of universities have become one of the necessary constraints to prevent the spread and reduce the incidence of COVID-19.

The problems identified during the implementation of the distance learning format served as an incentive for revising the existing approaches to teaching methods in higher education. In such a model, the traditional interaction of students and teachers, practical, scientific and social activities in the usual forms are combined with the use of online courses and simulators, with synchronous learning in a distance format, and provided with digital technologies. It is obvious that the use of traditional approaches in combination with digital technologies will make the higher education system more advanced and competitive.

The situation with the pandemic made it possible to identify, in some cases, the lack of flexible approaches in educational processes, which represent an obstacle to ensuring the relevance of higher education in the era of global digitalization and changing social realities. (Maitra S., 2020)

It became obvious that the existing infrastructure of universities, as well as digital resources, are not sufficiently developed to effectively promote the distance learning mode. It is necessary to accelerate the development of digital technologies and relevant practices of the educational process, to stimulate the improvement of the methodological qualifications of teachers.

The experience of a large-scale transition to distance learning has become a starting point on the path of development of higher education. It showed that there are problems and tasks that cannot be solved without digital technologies and remote format. Most of the teachers and students experienced new opportunities and were able to work in this mode. However, the accumulated fatigue from the high pace with which the transition was made creates conditions for a return to the pre-digital format. The lessons learned and experience from the current situation can serve to form a new model of universities' activity, as well as education more resistant to external challenges and productive development of the economy and society as a whole.

\section{ACKNOWLEDGEMENT}

This work has been financially supported by the Grant of the President of the Russian Federation №. HШ2668-2020.6 «National-Cultural and Digital Trends in the Socio-Economic, Political and Legal Development of the Russian Federation in the 21st Century».

\section{REFERENCE LIST}

Irina Gronik (2020). Distance Learning: A New Perspective to the Future. 10th International Conference The Future of Education - Virtual Edition. Edited by Pixel. Florence, Italy, pp. 203-207.

Ekaterina Kupchina (2020) The university course "Protection of Intellectual Rights" in the training of a corporate lawyer. 10th International Conference The Future of Education - Virtual Edition. Edited by Pixel. Florence, Italy, pp. 285-289

Belousova A., llyashevich M., Kupchina Y., Belousov A. (2017) Students perceptions on teaching style within public international law curriculum: a case of Russia. Eurasia Journal of Mathematics, Science and Technology Education. Vol. 13. No. 10. pp. 6945-6952.

Dudin, M.N., Shakhov, O.F., Shakhova, M.S., Rusakova, E.P., Sizova, Y.S. (2019) Digital technologies as a driver of intellectual stratification of human resources: socio-economic inequality. International Journal of Recent Technology and Engineering. Vol. 8. No. 2, 4436-4440. 
Dudin, M.N., Ivashchenko, N.P., Frolova, E.E., Abashidze, A.H. (2017) Institutional approach to the establishment of a structural model of the Russian academic environment development. European Journal of Contemporary Education. Vol. 6, No. 1, 22-38.

Dudin, M.N., Bezbakh, V.V., Frolova, E.E., Galkina, M.V. (2018) The models of higher education in Russia and European countries at the beginning of the XXI century: the main directions of development. European Journal of Contemporary Education. Vol. 7, No. 4. 653-667.

Inshakova, A.O., Frolov, D.P. (2016) On the formation of a new methodology for scientific, legal research in the field of nanotechnology and nano industry. Vestnik Permskogo universiteta. Yuridicheskie nauki. 32, pp. $133-143$

IAU (2020) The Impact of COVID-19 on Higher Education around the World URL: https://iauaiu.net/Covid19-Higher-Education-challenges-and-responses (Date of access: 08.12.2020) Maitra, S., Robinson, J. (2020) Higher Education after COVID-19 URL: https://www.researchgate.net/publication/341504615 (Date of access: 10.12.2020) 